\title{
MIGRAÇÃO DE DUNAS E O PROCESSO DE SOTERRAMENTO NO LITORAL DE BARROQUINHA, CEARÁ, BRASIL
}

\author{
Dunes migration and burial process \\ in the coast of Barroquinha, Ceará, Brazil
}

\author{
Renan Gonçalves Pinheiro Guerra ${ }^{1^{*}}$, Andréa de Sousa Moreira ${ }^{1}$, João Rafael Muniz Silva ${ }^{2}$, \\ Hermógenes Henrique Oliveira Nascimento ${ }^{1}$, Eduardo Lacerda Barros ${ }^{3}$ \\ ${ }^{1}$ Célula de Conservação da Diversidade Biológica (Cedib/Cobio), Secretaria do Meio Ambiente \\ (Sema) do Estado do Ceará. \\ ${ }^{2}$ Companhia de Água e Esgoto do Ceará (Cagece). E-mail: rafael.muniz@cagece.com.br \\ 3 Instituto de Ciências do Mar (Labomar), Universidade Federal do Ceará (UFC). \\ *Autor para correspondência: renan.Igco@gmail.com
}

\begin{abstract}
RESUMO
A migração dos corpos dunares no litoral cearense enuncia a intensa dinâmica eólica característica de litorais semiáridos nordestinos. Nesse sentido, este trabalho buscou analisar o processo de migração das dunas e sua relação com a questão dos soterramentos no litoral de Barroquinha. As taxas de migração das dunas foram definidas pela extensão Digital Shoreline Analysis System (DSAS), nas quatro áreas de interesse de Bitupitá e localidades de Venâncio e Curimã. A área de avanço das dunas foi obtida por meio do método polígono de mudanças. A migração das dunas no período de 2002 a 2014 evidenciou maior média das taxas de migração nas áreas 1 e 2, com 18,53 m/ano e 19,33 m/ano, e valores inferiores de 12,40 m/ano e 3,59 m/ano nas áreas 3 e 4 . Ações de mobilização e sensibilização das comunidades são fundamentais para adequação da dinâmica socioespacial aos efeitos da migração dos corpos dunares.
\end{abstract}

Palavras-chave: dunas, dinâmica eólica, soterramento.

\section{ABSTRACT}

The migration of the dunes enunciates the intense aeolian dynamics characteristic of the northeastern semiarid coast. In this sense, this work aims to analyze the process of dune migration 
and its relationship with the issue of burials on the coast of Barroquinha. Dune migration rates were defined using the extension Digital Shoreline Analysis System (DSAS) in the four areas of interest of Bitupitá, Venâncio and Curimã. The dune advance area was obtained using the change polygon method. It was found that the dune migration rate from 2002 to 2014 showed the highest average in areas 1 and 2, with $18.53 \mathrm{~m} /$ year and $19.33 \mathrm{~m} /$ year, and lower values of $12.40 \mathrm{~m} / \mathrm{year}$ and $3.59 \mathrm{~m} /$ year in areas 3 and 4 . Actions of mobilization and community awareness are essential to adapt the socio-dynamic effects of the dynamics of these dunes.

Keywords: dunes, aeolian-dynamics, burials.

\section{INTRODUÇÃO}

As dunas costeiras são ecossistemas terrestres únicos situados na transição entre ambientes marinhos e continentais. Assim como outros habitats costeiros, os sistemas dunares são extremadamente frágeis e facilmente vulneráveis às intervenções humanas, isto considerando os aspectos naturais inerentes a sua formação, seu desenvolvimento e sua evolução (Seoane; Fernández \& Pascual, 2007; Santana-Cordero; Monteiro-Quitana \& HernándezCalvento, 2016).

A formação dos campos dunares estabelece feições distintas, as quais são definidas através de diferenciações estreitamente relacionadas a variáveis como: direção do vento predominante, disponibilidade sedimentar, conformação da superfície percorrida pelos sedimentos desde sua disponibilização, ação dos ventos na faixa de praia e localização dessas dunas dentro do segmento costeiro (Pinheiro et al., 2013). Na zona costeira do Ceará, uma condição particular para a intensa mobilidade das dunas é a constante orientação dos ventos do quadrante leste para o oeste (Maia, 1998). A estação seca, em média, é marcada por ventos oriundos do quadrante leste, enquanto na estação chuvosa são dominantes os ventos de nordeste. Associados a isso, a ocorrência de praias dissipativas e intermediárias e o contínuo by pass de sedimentos arenosos nos promontórios contribuem para o desenvolvimento de significativos campos de dunas na zona costeira cearense (Maia, 1998; Claudino-Sales, 2002; Morais et al., 2006).

Embora exista conhecimento arraigado que as áreas ao longo da costa cearense são amplamente trabalhadas pela dinâmica eólica, esse aspecto, muitas vezes, não é bem avaliado ou ponderado no momento da escolha do local ou durante a elaboração de projetos para sua ocupação (Carvalho, 2015). Ante o exposto, o objetivo deste trabalho é analisar o processo de migração das dunas e sua relação com a questão dos soterramentos de infraestruturas e comunidades do litoral de Barroquinha. Nesse ínterim, foram consideradas as áreas prioritárias para monitoramento e ações mitigatórias considerando o estágio da frente de avanço dos corpos dunares na planície litorânea do município.

\section{MATERIAIS E MÉTODOS}

\section{Área de estudo}

O município de Barroquinha está situado na costa do extremo oeste do Ceará, inserido no setor IV de acordo com a Divisão de Implementação das Ações do Gerenciamento Costeiro (Gerco-CE). O município está localizado a $385 \mathrm{~km}$ de Fortaleza e apresenta área 
territorial de $383 \mathrm{~km}^{2}$, perfazendo divisa com o estado do Piauí a oeste, na confluência de canais na desembocadura do rio Timonha; a leste, com o município de Camocim; e ao sul, com os municípios de Chaval e Granja (Figura 1). Sua população estimada no Censo de 2010 era de 14.476 habitantes, sendo mais expressiva nos setores censitários da sede do município e no distrito de Bitupitá (74\% da população total do município).

Figura 1 - Localização da área de estudo e setores ambientais da planície litorânea do município de Barroquinha, com destaque para as áreas de interesse da análise de migração dos corpos dunares

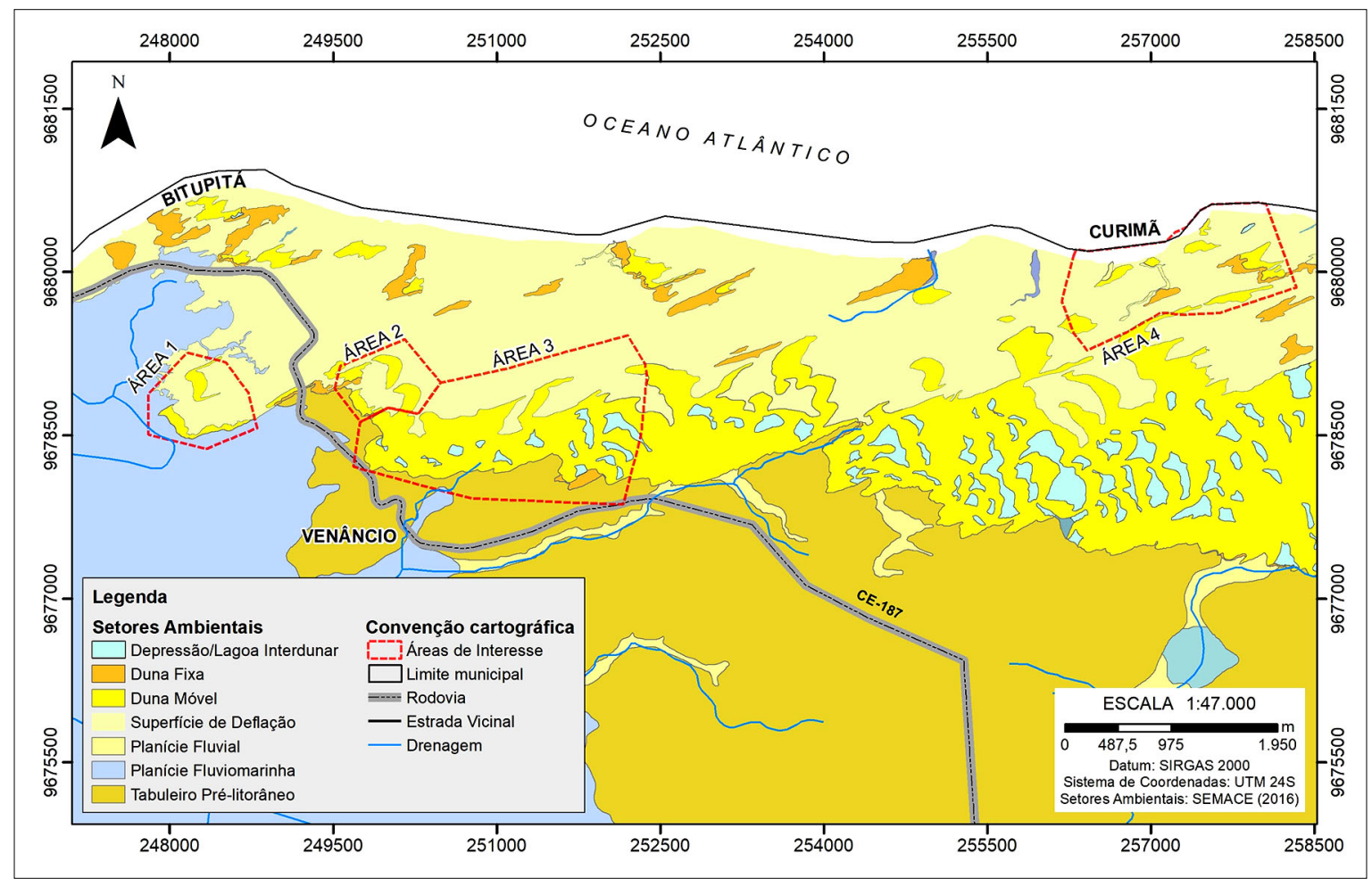

Fonte: Elaborada pelos autores.

Inseridas no distrito de Bitupitá, as quatro áreas de interesse para análise da dinâmica de migração de dunas estão contempladas próximo à sede de Bitupitá (01) e nas localidades de Venâncio (02) e Curimã (01). As áreas estão estabelecidas em quase a totalidade sobre a planície litorânea de Barroquinha, que adentra mais de $2 \mathrm{~km}$ nesse trecho do litoral. Entre os principais setores ambientais da planície litorânea do município estão a planície fluviomarinha do rio Timonha, os expressivos campos de dunas e as superfícies de deflação eólica.

\section{Coleta e análise de dados}

A análise do processo de migração das dunas no litoral de Barroquinha contou inicialmente com o levantamento da bibliografia e base cartográfica do município de Barroquinha. Foram consultados os acervos digitais das bibliotecas da Universidade Federal do Ceará (UFC), do Instituto de Ciências do Mar (Labomar/UFC) e da Universidade Estadual do Ceará (Uece). O banco de artigos do Portal de Periódicos da Coordenação de Aperfeiçoamento de Pessoal de Nível Superior (Capes) e do Science Direct também foi explorado. 
A base cartográfica e o acervo de imagens foram obtidos através de projetos específicos, como o projeto "Polo Ceará Costa do Sol", do Instituto de Pesquisa e Estratégia Econômica do Ceará (Ipece), e o projeto "Reestruturação e atualização do mapeamento do projeto Zoneamento Ecológico-Econômico do Ceará - Zona Costeira e Unidades de Conservação", da Superintendência Estadual do Meio Ambiente do Estado do Ceará (Semace). As imagens obtidas contemplaram um universo amostral de 12 anos, correspondendo ao período de 2002 a 2014.

O reconhecimento de campo abrangeu o levantamento de informações ao longo de quatro áreas de interesse inseridas no distrito de Bitupitá e nas localidades de Venâncio e Curimã. O campo foi realizado durante os dias 27 e 28 de novembro de 2018 com o intuito de conhecer a dinâmica local e o processo de soterramento evidenciado no litoral do município de Barroquinha. Durante o levantamento in situ, foi realizado registro de aspectos específicos como: 1) superfícies de transporte eólico; 2) delimitação das frentes de avanço dos corpos dunares; e 3) identificação de áreas colapsadas pelo soterramento, ou em sua iminência. Essa etapa contou com o auxílio da equipe técnica da Prefeitura Municipal de Barroquinha, responsável também pela aquisição de imagens aéreas através de sobrevoo panorâmico realizado com o Drone Phantom 4 Advanced da DJI.

A definição das taxas de migração das dunas contou inicialmente com a vetorização dos limites de base da face de deslizamento e das marcas de migração dos corpos dunares, evidenciados nas imagens disponíveis para as áreas de interesse (Tabela I). As taxas de migração foram obtidas através da adaptação da extensão Digital Shoreline Analysis System (DSAS), v. 4.2 para ArcGis 10.3, nas quatro áreas de interesse supracitadas. Em termos gerais, o DSAS trabalha gerando transectos ortogonais a uma linha de base determinada pelo usuário (baseline), com espaçamento definido, e calcula as taxas de variação que são mostradas na tabela de atributos em metros (Farias \& Maia, 2010). Para isso, o DSAS utiliza-se de vários métodos estatísticos que tomam como base as diferenças entre as posições das linhas de referência ao longo do tempo. Os métodos estatísticos empregados neste trabalho foram o EPR (End Point Rate) e LRR (Linear Regression Rate).

Tabela I - Base de dados e informações utilizadas nos períodos analisados

\begin{tabular}{|c|c|c|c|c|c|c|c|}
\hline Área & Tipo de imagem & $\begin{array}{l}\text { Resolução }(\mathrm{m}) / \\
\text { precisão }\end{array}$ & Data & $\begin{array}{l}\mathrm{N}^{0} \text { de } \\
\text { transec. }\end{array}$ & Espaçamento (m) & $\begin{array}{c}\text { Comp. } \\
\text { transec. }(\mathrm{m})\end{array}$ & $\begin{array}{l}\text { Período analisado } \\
\text { (anos)/métod. }\end{array}$ \\
\hline A-1 & & & & 10 & \multirow{4}{*}{50} & & \multirow{4}{*}{ 12/EPR ${ }^{\mathrm{a}}$ e LRR ${ }^{\mathrm{b}}$} \\
\hline A-2 & QUICKBIRD $^{1}$ & 0,61 & $\begin{array}{l}17 / 8 / 2002^{1} \\
20 / 5 / 2007^{2}\end{array}$ & 11 & & 350 & \\
\hline A-3 & Aerofoto $^{3}$ & 0,5 & $18 / 7 / 2014^{3}$ & 54 & & & \\
\hline A-4 & & & & 13 & & 800 & \\
\hline
\end{tabular}

${ }^{a}$ EPR - Taxa do Ponto de Extremidade / bLRR - Regressão Linear Simples.

Em sequência, foram delimitadas as áreas de avanço dos campos de dunas com o método do polígono de mudanças. A abordagem do polígono de mudança utiliza duas linhas de períodos distintos para construir uma topologia de polígono que representa a diferença total entre posição das linhas de referência (Smith \& Cromley, 2012). A criação dos polígonos de mudanças foi realizada com o auxílio do software ArcGis 10.3, com o comando Data Manegement Tools - Features, transformando shapes de linhas em polígonos. O somatório das áreas do conjunto de polígonos aproximou-se da mudança da área total de avanço das dunas ao longo da escala espaçotemporal analisada. 


\section{RESULTADOS E DISCUSSÕES}

\section{Caracterização do sistema de dunas do Ceará}

As dunas no litoral do Ceará apresentam orientação predominante de leste para oeste, paralelamente aos alísios, apresentando feições em meia-lua, como barcanas e parabólicas (Claudino-Sales \& Carvalho, 2014). Além disso, são verificados alinhamentos de eolianitos principalmente na costa noroeste do Ceará, totalizando uma área de $30,63 \mathrm{~km}^{2}$ (Carvalho et al., 2009; Maia et al., 2012). Os campos de dunas fixadas por vegetação e móveis no estado do Ceará totalizam uma área de $331 \mathrm{~km}^{2}$ (Maia et al., 2012). A altimetria das dunas móveis varia em média de $15 \mathrm{~m}$ no segmento leste até $50 \mathrm{~m}$ na porção oeste, refletindo o aumento da intensidade do vento em direção a oeste e a disponibilidade de sedimentos de fino a médio (Smith \& Morais, 1984; Claudino-Sales \& Carvalho, 2014).

Medições realizadas em dunas do litoral oeste do Ceará evidenciaram taxas de migração variáveis. Em Jericoacoara, Maia et al. (2000) constataram, através de comparação de aerofotografias do período de 1958 a 1988, taxas variando entre 14,6 m/ano e $21 \mathrm{~m}$ / ano. Meireles (2011) obteve taxas semelhantes ao analisar os campos de dunas móveis do mesmo trecho costeiro, com deslocamento de 20,6 m/ano para o período de 2006 a 2011. Nas dunas barcanas e barcanoides, situadas nas localidades de Flecheiras, Baleia e Paracuru, Carvalho, Maia e Dominguez (2006) definiram taxas de migração considerando a medição das distâncias entre os arcos das marcas de migração. Conforme os dados medidos em campo por Carvalho, Maia e Dominguez (2006), a média geral de migração das dunas variou entre 14 $\mathrm{m} /$ ano e $23 \mathrm{~m} /$ ano para as dunas barcanoides e de $15 \mathrm{~m} /$ ano a $32 \mathrm{~m} /$ ano para as barcanas. Geralmente, a taxa de migração varia entre $9 \mathrm{~m} /$ ano e $22 \mathrm{~m} /$ ano, com média de aproximadamente $11 \mathrm{~m} /$ ano (Jimenez et al., 1999).

Os diversos estudos já realizados no âmbito do litoral cearense enunciam a intensa dinâmica eólica que caracteriza o aspecto de semiaridez do litoral, repercutindo no transporte sedimentar e na formação de extensos campos de dunas. Por isso, as interferências antrópicas nesse processo modificam a trajetória, a energia envolvida e o volume de areia em transporte, culminando em uma nova dinâmica, normalmente regida pelo predomínio de fenômenos erosivos (Meireles; Silva \& Thiers, 2006).

Em diversos trechos costeiros, expressivo volume de areia, que antes transitava pela planície costeira, na forma de dunas, foi desviado ou fixado pela expansão urbana e, assim, impedido de alcançar a faixa de praia (Meireles; Silva \& Thiers, 2006; Meireles, 2011; Carvalho, 2015). Aos corpos dunares que ainda permanecem com transporte ativo resta prosseguir no caminho destinado naturalmente para sua migração, atento às "barreiras" que foram sendo implantadas historicamente nas superfícies de deflação sem a devida compreensão dos riscos concernentes à degradação desse sistema ambiental e soterramento de infraestruturas urbanas.

\section{Dunas móveis de Barroquinha e a questão dos soterramentos}

No município de Barroquinha, as taxas de migração dos corpos dunares expuseram valores variáveis, estando condicionados: 1) à superfície disponível para erosão e transporte dos sedimentos (Fetch eólico); 2) à dimensão do corpo dunar; e 3) às rugosidades das superfícies de migração das dunas. As diferentes taxas de migração dos corpos dunares para o 
período de 2002 a 2014 estão descritas por área de interesse na Tabela II. Além disso, estão estabelecidos ainda os valores das áreas soterradas no intervalo de tempo observado.

Tabela II - Valores das taxas de migração das dunas e área de avanço no período de 2002 a 2014

\begin{tabular}{l|c|c|c}
\hline \multicolumn{1}{c|}{ Área de interesse } & Taxa de variação (m/ano) & Área de avanço (ha) & $\begin{array}{c}\text { Intervalo de } \\
\text { observação }\end{array}$ \\
\hline $\begin{array}{l}\text { Área 1 - Bitupitá1 } \\
\text { (rio Timonha) }\end{array}$ & 18,53 & $7,41 / 5,15$ & $2002-2014$ \\
Área 2 - Venâncio ${ }^{2}$ & 19,41 & $5,87 / 5,07 / 5,41$ & \\
Área 3 - Venâncio (sede) & 12,40 & 30,88 & \\
Área 4 - Curimãs & 3,20 & 3,29 & \\
\hline
\end{tabular}

${ }^{1}$ Área de interesse com a presença de dois corpos dunares. ${ }^{2}$ Área de interesse com três corpos dunares.

A migração das dunas no período de 2002 a 2014 evidenciou maior média das taxas de migração nas áreas 1 e 2, com 18,53 m/ano e 19,41 m/ano, e valores inferiores de 12,40 $\mathrm{m} /$ ano e 3,20 m/ano nas áreas 3 e 4, seguindo o critério das médias obtidas pelo método estatístico EPR. A variação nos valores de migração registrada foi influenciada, em sua máxima, pela ocorrência de corpos dunares isolados e limitada existência de obstáculos na superfície de migração. Em situação antagônica, os valores mínimos refletem superfície de migração com substancial resistência ao deslocamento da duna provocado pela existência de vegetação com fisionomia arbustiva/arbórea (Figura 2).

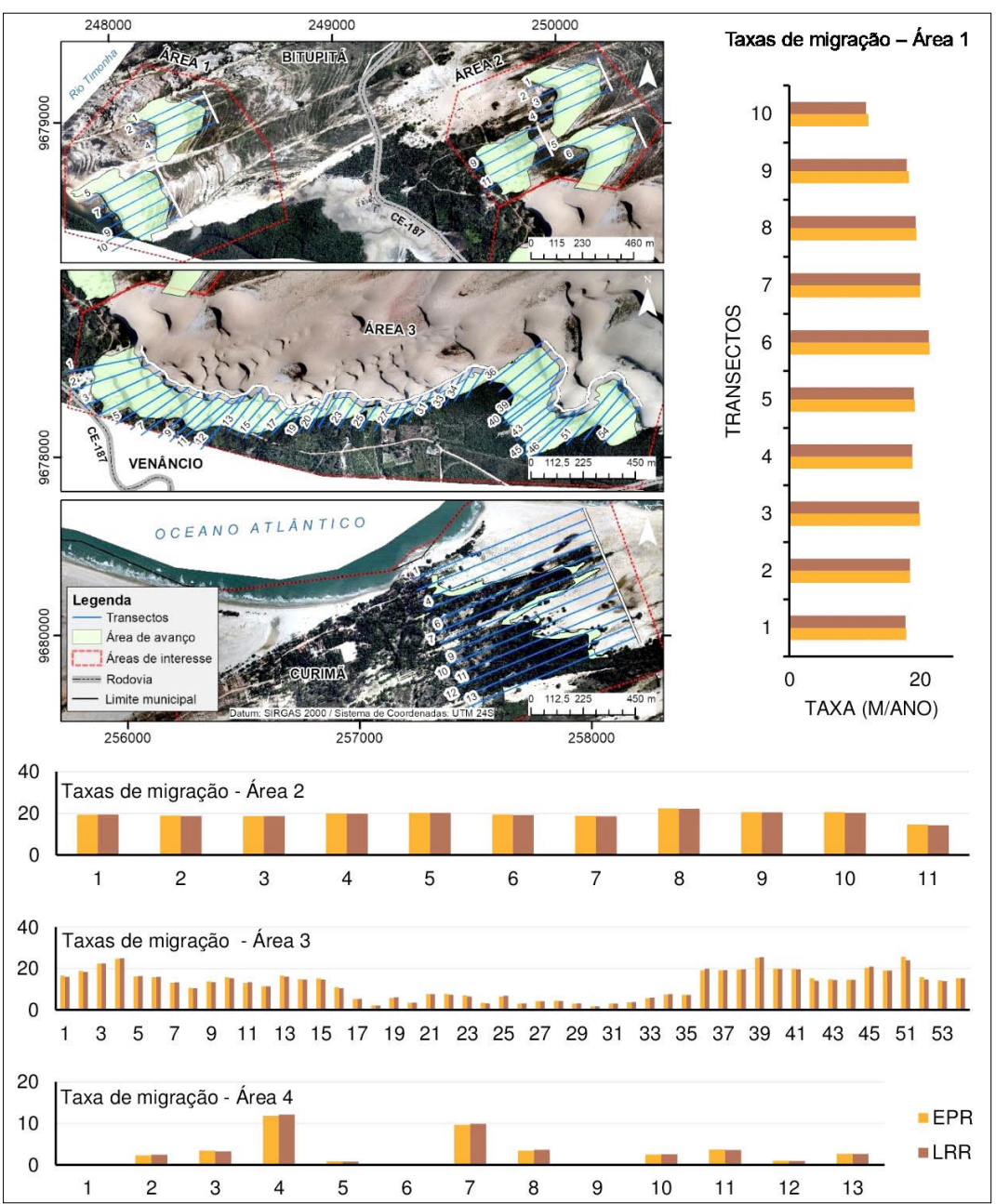

Figura 2 - Transectos DSAS e taxas de migração das dunas nas áreas de interesse

Fonte: Elaborada pelos autores. 
As áreas 1 e 2 constituem corpos dunares fragmentados que se deslocam com velocidade superior aos demais trechos analisados. As dunas do tipo barcanas dos trechos em questão expõem maior deslocamento nas bordas, com taxas de migração de 19,94 m/ano (área 1 - transecto 3) e 19,91 m/ano (área 2 - transecto 4) (ver Figura 2). As dunas barcanoides apresentaram valores de migração superiores a 21,42 m/ano (área 1 - transecto 6) e 22,4 m/ano (área 2 - transecto 8). Em ambas as áreas, a superfície de transporte eólico apresenta menor resistência ao deslocamento dos corpos dunares, em especial nas dunas que entornam no canal estuarino do rio Timonha (Figura 2). Na área 2, é importante destacar que as dunas migram em sentido de colisão com a Rodovia CE-187, distando da sua face de deslizamento para o pavimento da rodovia, aproximadamente $420 \mathrm{~m}$. Em somatória, os avanços verificados no período de 2002 a 2014 representaram soterramento de 12,56 ha (área 1) e 16,35 ha (área 2).

Outra situação está disposta na área 3, segmento contíguo à localidade de Venâncio, que constitui área de campo de dunas com maior dimensão. O campo de dunas está em área de retroalimentação ativa promovida pelo abastecimento sedimentar de corpos dunares mais recentes, caracterizado pelas feições mais próximas do trecho costeiro de Curimã. A taxa média de migração expõe valor de 12,4 m/ano no método EPR, representando área de avanço de 30,88 ha. Apesar disso, a migração das dunas na área 3 enunciou intenso deslocamento espacial em duas frentes: 1) transectos 1 a 16 - taxa média de 15,62 $\mathrm{m} /$ ano (método EPR) e 15,46 m/ano (LRR); e 2) transectos 36 a 54 - taxa média de 18,51 m/ ano (EPR) e 18,31 m/ano (LRR).

Nesse ínterim, os transectos 17 a 35 apresentam taxa bastante inferior aos valores obtidos nas frentes de migração das dunas adjacentes, cujo valor médio representa 4,88 m/ano (EPR) e 4,86 m/ano (LRR) (ver Figura 2). Esse aspecto apresenta relação com a disposição de obstáculos naturais/antrópicos na superfície de transporte eólico ativo, retardando a migração do corpo dunar no trecho em questão. Em situação semelhante à área 2, a migração das dunas na área 3 tem culminado no soterramento de infraestruturas urbanas e trecho viário da CE-187, que interliga a sede de Barroquinha ao distrito de Bitupitá (Figura 3).

Na comunidade de Curimã, a migração das dunas entre 2002 e 2014 enunciou o avanço de área inferior às demais áreas levantadas neste estudo, correspondendo ao valor de 3,20 ha. Esse aspecto é um reflexo das menores taxas de migração identificadas na área 4, com valor médio de 3,20 m/ano. No entanto, taxas de migração mais expressivas são indicadas nos flancos das dunas representados pelos: 1) transecto 4 - com 11,87 m/ano (EPR) e 12,09 m/ano (LRR); e 2) transecto 7 - com 9,68 m/ano (EPR) e 9,88 m/ano (LRR) (ver Figura 2). Nesse sentido, a existência de superfícies de transporte eólico com vegetação mais espaçada contribuiu para a migração acelerada nos flancos dos corpos dunares, enquanto nas frentes de avanço mais centrais a migração é retardada devido ao adensamento da vegetação. Na localidade de Curimã também é identificado o processo de soterramento, aspecto que retrata uma lacuna contínua no planejamento da ocupação das áreas de by pass de sedimentos no litoral (Figura 4). Apesar das dificuldades vivenciadas, é possível identificar a persistência em lotear áreas de transporte eólico intenso, a exemplo das superfícies de deflação. 
Figura 3 - Estrutura da Escola de Ensino Fundamental Nossa Senhora do Perpétuo do Socorro em 2012 e posterior ao processo de soterramento da escola (seta amarela) e de trecho da CE-187 na localidade do Venâncio

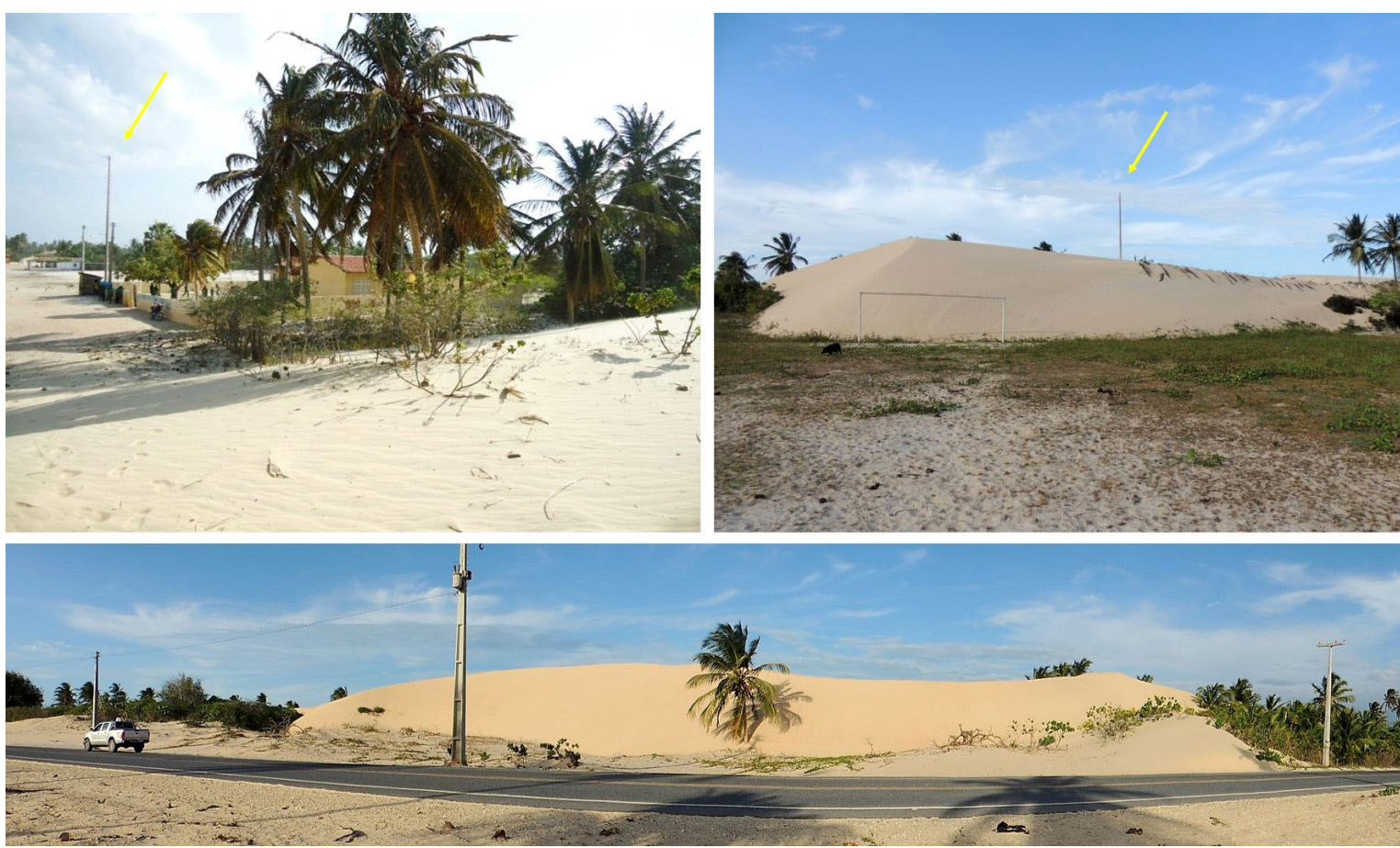

Fonte: Apeoc (2012) e Cedib (2018).

Figura 4 - Migração de dunas e soterramento de estrada de acesso à localidade de Curimã, com destaque para o loteamento de áreas com transporte eólico intenso
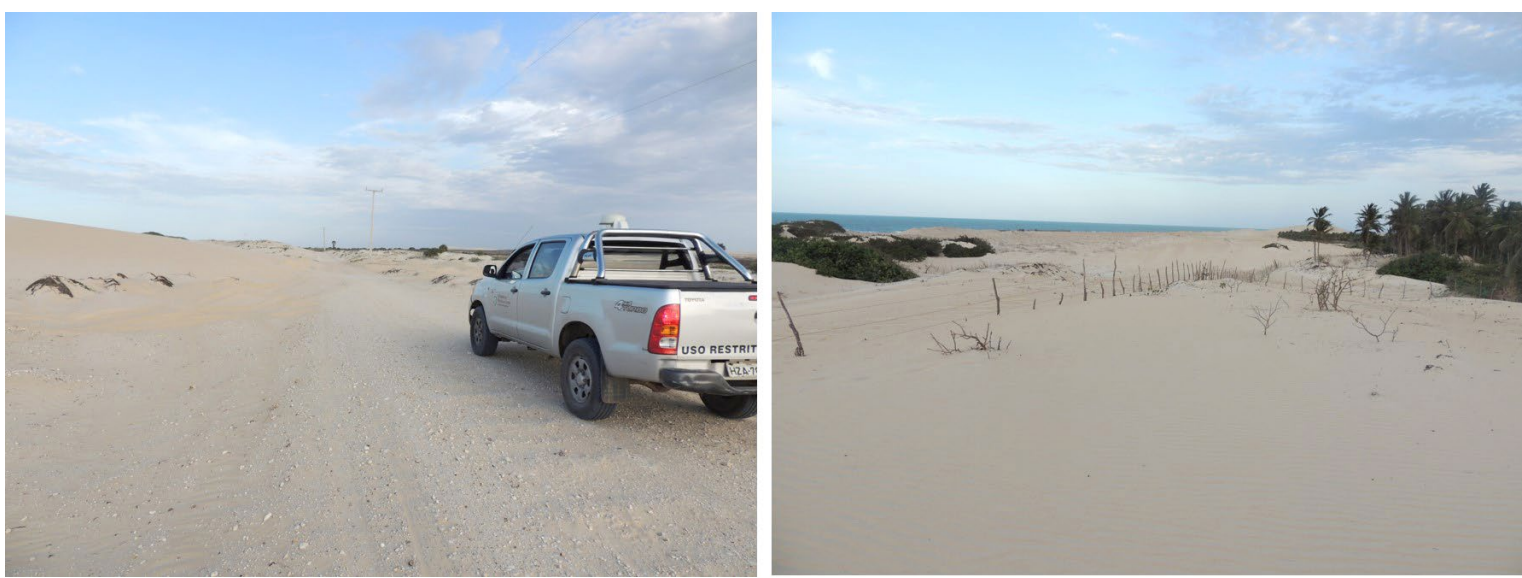

Fonte: Cedib (2018).

\section{CONCLUSÕES}

A abundante disponibilidade de material sedimentar aliada à intensidade dos ventos e existência de barramentos na superfície de transporte eólico contribuem para a formação de corpos dunares expressivos em suas dimensões. Nesse aspecto, considerando o processo histórico de ocupação dos espaços costeiros sem o devido planejamento, é cada vez mais importante evidenciarmos áreas com riscos de soterramentos. Assim, torna-se neces- 
sário o estabelecimento de medidas que permitam, inicialmente, conhecer de maneira pormenorizada o problema para, posteriormente, subsidiar políticas públicas que garantam a convivência com os efeitos do processo natural de migração dos campos de dunas, como: 1) identificação de áreas e quantificação de infraestruturas em iminência de colapso pelo soterramento; 2) realização de estudos que fomentem o conhecimento em detalhe da dinâmica local das dunas e indicação de técnicas de contenção do transporte eólico em áreas pontuais; 3) interlocução com outros municípios que expõem desafios semelhantes com o processo de migração de campos de dunas móveis; e 4) articulação de contato com o Instituto Chico Mendes de Conservação da Biodiversidade (ICMBio), tendo em vista a inserção das áreas de interesse na Área de Proteção Ambiental (APA) do Delta do Parnaíba. Nesse cenário, as ações de mobilização e sensibilização das comunidades são fundamentais para execução e manutenção dos projetos que visem adequar a dinâmica socioespacial aos efeitos da migração dos corpos dunares.

\section{REFERÊNCIAS BIBLIOGRÁFICAS}

Carvalho, A.M.; Maia, L.P. \& Dominguez, J.M.L. Caracterização do processo de migração das dunas de Flexeiras, Baleia, Paracuru e Jericoacoara, costa noroeste do Ceará. Arquivos de Ciências do Mar, Fortaleza, v. 39, n. 1-2, p. 44-52, 2006.

Carvalho, A.M.; Claudino-Sales, V.; Maia, L.P. \& Castro, J.W.A. Eolianitos de Flecheiras/ Mundaú, costa noroeste do estado do Ceará, Brasil: registro ímpar de um paleo-sistema eólico costeiro, p. 1-10, in Schobbenhaus, C.; Campos, D.A.; Queiroz, E.T.; Winge, M. \& Berbert-Born, M.L.C. (orgs.). Sítios Geológicos e Paleontológicos do Brasil. CPRM, v. 2, p. 515, 2009.

Carvalho, A.M. de. Análise de risco da ocupação do espaço costeiro sobre a dinâmica eólica: o caso de um hotel em Camocim, estado do Ceará. Arquivos de Ciências do Mar, Fortaleza, v. 48, n. 2, p. 32-40, 2015.

Claudino-Sales, V. La zone côtière de l'état du Ceará, Nordeste du Brésil: du long terme au court terme. Tese de doutorado, URL de Géographie, Univesité Paris-Sorbonne, 549 p., Paris, 2002.

Claudino-Sales, V. \& Carvalho, A.M. de. Dinâmica costeira controlada por promontórios no estado do Ceará, Nordeste do Brasil. Geociências, v. 33, n. 4, p. 579-595, 2014.

Farias, E.G.G. \& Maia, L.P. Uso de técnicas de geoprocessamento para a análise da evolução da linha de costa em ambientes litorâneos do estado do Ceará, Brasil. Revista de Gestão Costeira Integrada, v. 10, n. 4, p. 521-544, 2010.

Jimenez, J.A.; Maia, L.P.; Serra, J. \& Morais, J.O. Aeolian dune migration along the Ceará coast, North-Eastern Brazil. Sedimentology, v. 46, n. 4, p. 689-701, 1999.

Maia, L.P. Procesos costeros y balance sedimentário a lo largo de Fortaleza (NE-Brasil): implicaciones para uma gestióm adecuada de la zona litoral. Tese de doutorado, Departamento de Ecologia, Faculdad de Biologia, Universidad de Barcelona, 269 p., Barcelona, 1998.

Maia, L.P.; Jimenez, J.A.; Freire, G.S.S. \& Morais, J.O. Dune migration and aeolian transport along Ceará (NE Brasil): downscaling and upscaling aeolian induced processes. Arquivos de Ciências do Mar, Fortaleza, v. 33, p. 99-106, 2000. 
Maia, L.P.; Leal, R.L.V.; Pinheiro, L.S.; Cunha, E.M.S. \& Serra, J. Gestão de dunas costeiras e conflitos de usos nos estados do Ceará e Rio Grande do Norte-Nordeste do Brasil, p. 149158, in Rodríguez-Perea, A.; Pons, O.X.; Roig-Munar, F.X.; Martín-Prieto, 1.A.; Mir-Gual, M. \& Cabrera, 1.A. (eds.). La gestión integrada de playas y dunas: experiencias en Latinoamérica y Europa, Sociedad Historia Natural Balears, Palma de Mallorca, 2012.

Meireles, A.J.A.; Silva, E.V. da \& Thiers, P.R.L. Os campos de dunas móveis: fundamentos dinâmicos para um modelo integrado de planejamento e gestão da zona costeira. GEOUSP: Espaço e Tempo, São Paulo, v. 10, n. 1, p. 101-119, 2006.

Meireles, A.J.A. Geodinâmica dos campos de dunas móveis de Jericoacoara/CE-BR. Mercator, Fortaleza, v. 10, n. 22, p. 169-190, 2011.

Morais, J.O.; Freire, G.S.; Pinheiro, L.S.; Souza, M.J.N.; Carvalho, A.M. \& Pessoa, P. R.S. Capítulo Ceará, p. 132-134, in Muehe, D. (org.). Erosão e progradação do litoral brasileiro, Rio de Janeiro: Ministério do Meio Ambiente, 476 p., 2006.

Pinheiro, M.V.A.; Moura-Fé, M.M.; Freitas, E.M.N.; Costa, A.T.; Aguiar, A.C.S. \& Sombra, E.T.P. Dunas móveis: área de preservação permanente? Sociedade E Natureza, Uberlândia, v. 3, n. 25, p. 595-607, 2013.

Santana-Cordero, A.M.;Monteiro-Quintana,M.L. \&Hernández-Calvento, L. Reconstruction of the land uses that led to the termination of an arid coastal dune system: the case of the Guanarteme dune system (Canary Islands, Spain). Land Use Policy, v. 55, p. 73-85, 2016.

Seoane, C.L.V.; Fernández, J.B.G. \& Pascual, C.V. Manual de restauración de dunas costeras. Ministerio de Medio Ambiente: Dirección General de Costas, 258 p., España, 2007.

Smith, M.J. \& Cromley, R.G. Measuring historical coastal change using GIS and the change polygon approach. Transactions in Gis, v. 16, n. 1, p. 3-15. 2012. 